\title{
JAPANESE PRACTICE FOR ESTIMATING THE EXPECTED MAXIMUM EARTHQUAKE FORCE AT A NUCLEAR POWER PLANT SITE
}

\author{
Syun'itiro Omote* Yorihiko Ohsaki** \\ Toshihiro Kakimi*** and Tokihoko Matsuda****
}

\begin{abstract}
SYNOPSIS:
Nuclear power plants built in seismic zones should be designed and constructed in such a way that they produce no radiation hazard in the event of a severe earthquake. In order to find a reasonable solution to this problem the first step that needs to be taken is to make an estimation of the maximum earthquake force to be expected at the site. This paper gives the basic Japanese views on this problem. Levels of the strongest design earthquake $\mathrm{S}_{1}$ and extreme design earthquake $\mathrm{S}_{2}$ are explained and methods for deriving $\mathrm{S}_{1}$ and $\mathrm{s}_{2}$ earthquakes from active faults are also described.
\end{abstract}

\section{INTRODUCTION :}

Increasing numbers of large civil and structural engineering projects are being undertaken around the world. Because of the consequences of failure of these structures in earthquake it has become necessary to give detailed consideration to their earthquake-resistant design.

In the case of nuclear power plants the problem of the safety of these plants if they are subjected to earthquake attack must be considered more seriously and carefully. Nuclear power plants should be designed much more conservatively than other ordinary buildings as the consequences of accidents which might be caused by earthquake attack are much more serious.

Seismic design criteria for nuclear power plants are therefore much more stringent than criteria for ordinary buildings and structures, so that the plant and all other equipment and facilities of the plant can resist the violent earthquake vibration without causing any potential radiation hazard even if a large earthquake should take place in the vicinity of the site, and if some of the noncritical parts of the plant might be damaged.

In order to find a reasonable solution to this problem the first step which must be taken is to estimate the maximum earthquake force to be expected at the site during the lifetime of the nuclear power plant.

The problem of estimating the maximum earthquake force at a specific site has become a matter of increasing attention internationally. For example, in the compilation of the code of practice for

* Professor, Kyushu Sangyo Univ., Higashi-ku Fukuoka City, Japan.

* * Professor, Faculty of Engineering, The University of Tokyo.

*** Chief, Seismo-geological Section, Geological Survey of Japan.

****Associate Professor, Earthquake Research Institute, The University of Tokyo nuclear power plants, the International Atomic Energy Agency has given priority to the chapter on siting practices (supplemented by the Safety Guide in Earthquakes and Associated Topics for Nuclear Power Plant Siting) during compilation of the Code of Practice on Nuclear Power Plants.

In this paper the authors intend to discuss the basic views on this problem as are now commonly agreed upon by researchers in Japan.

2. BASIC EARTHQUAKE GROUND MOTIONS:

2.1 Concept of dual levels of earthquake motion

Because the severity of potential accidents is so great and because the uncertainties associated with destructive earthquakes are so large, nuclear power plant designs must be carefully planned so that the health and safety of the people in and near the site is assured.

For the purpose of carrying out suitable designs which could meet the above requirement, the level of the severity of the earthquake ground motion to be expected at the site must be evaluated in advance. Therefore, the setting up of the basic earthquake ground motions specific for each site will provide the most useful way of practice.

This site-specific basic ground motion is called here "the basic earthquake ground motion". A basic earthquake ground motion, however, needs to be defined relative to the level of the surface on which the earthquake motion is to be evaluated. The basic earthquake ground motion as used in this paper is derived from the earthquake motion at the free field of the base stratum surface in the proposed site. The free field of the base stratum surface is a nearly flat surface of the base stratum extending over a considerable area, and above which neither surface layers nor structures are assumed to be present. The base stratum is a firm base stratum which was formed in general in the Tertiary or earlier 
geological era and which is not weathered significantly.

In setting up the standard earthquake motion to be used as a design earthquake for a nuclear power plant, it is necessary to introduce the concept of dual earthquake levels for design.

\subsection{Basic Earthquake Motion $\mathrm{S}_{1}$ :}

The largest earthquake ground motion, among those which can reasonably be expected to be experienced at the site area during the lifetime of the nuclear power plant, is defined as the Basic Earthquake Ground Motion at the proposed site and is named $S_{\text {. }}$. The earthquake that gives the $S$ earthquake motion at

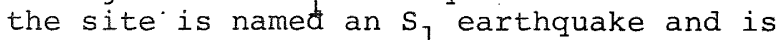
callea the "Maximum Design Earthquake".

\subsection{Basic Earthquake Ground Motion $\mathrm{S}_{2}$ :}

In view of the present knowledge of seismology, based upon the seismotectonic considerations, historic earthquakes experienced in the site region, and the characteristic nature of the active faults around the site area; and even though the probability of such event will be very low, we cannot neglect the possibility of the occurrence of an earthquake in the area near the site that gives a larger earthquake motion than $\mathrm{S}_{1}$. For ultimate safety requirement to the nuclear power plant, even if it may have a very low probability, the possible maximum level of earthquake motion should be taken into consideration. The earthquake that gives this $\left(S_{2}\right)$ earthquake motion at the site is named an $S_{2}$ earthquake and is also called the "Extreme Design Earthquake".

\section{GENERAL METHOD FOR THE DERIVATION OF THE BASIC EARTHQUAKE GROUND MOTIONS:}

\subsection{Earthquake and Earthquake Motion:}

Needless to say, our final goal is to derive the maximum earthquake ground motion and the extreme earthquake ground motion to be expected at the site area. The following procedure is proposed. Firstly, identify the earthquakes causing

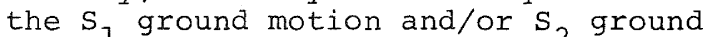
motion near the site area that are expected to occur in the near future at a location not far from the site. Secondly, the effect of these earthquakes at the site is evaluated. In practice, however it is not easy to evaluate correctly the effect of an earthquake at the site. In general, the magnitude and the distance between the earthquake focus and the site need to be known. However studies of the generation and propogation of the fault rupture formation, and the strong polarization of the seismic wave energy sent out from these fault movement, have given rise to the thought that the earthquake force that is effecting the site is related not only to the magnitude of the earthquake and the focal distance to the site; but also such items as dimension of the source, the relation between the orientation of the fault model and the aximuth of the site to the focus, the frequency characteristics of the earthquake waves at the origin, the duration time of the severe vibration, and the time dependent change in the shape of the envelope curve of the amplitudes of the earthquake waves. But in our discussion we do not intend to go into this detail. We shall try to find firstly, the way with which we can derive the maximum earthquake and the extreme earthquake at the site area and secondly, in consultation with the characteristic nature of the respective earthquakes to show the way by which we can derive the $S_{1}$ and $S_{2}$ earthquake ground motion at the site area. Following this principle, practical procedures for deriving the maximum design earthquake and the extreme design earthquake will be explained in section 4. In section 6 we will describe how to evaluate the earthquake design force to be expected at the proposed site from these earthquakes.

\subsection{Investigation in the Historical Earthquakes:}

For the purpose of deriving the $S_{1}$ and $S$ earthquake, important data are proviaed by investigations of the historical earthquakes that have taken place near the site. For this reason, as a first step, all the earthquakes that are considered to have given the intensity 5 or greater by the Japan Meteorological Agency Intensity Scale (which corresponds to the Intensity $73 / 4$ by the Modified Mercalli Intensity Scale) should be identified in the authorized earthquake catalogue. In Japan there is an authorative earthquake catalogue ${ }^{1-3}$ ) covering the period of 1500 years, beginning from 549AD. Even in this catalogue, however, there are many missing earthquakes, and much effort should be extended as to find new materials to shown the seismic activity in the site region in the past years; by examining the old newspapers, old written reports by public or rural authorities, ancient documents, and so on. All available data, on the earthquakes that have taken place in past years around the site region should be collected, magnitude, depth of focus, aftershock area, intensity including distribution of that earthquake including the maximum intensity at its epicentral area, detail on the earthquake damage together with the destruction rate of dwelling houses in severely damaged towns and villages, and the maximum acceleration estimated from the overturning of gravestones. It is desirable, that information be obtained on the relation between the earthquake damage and topography or ground conditions. In places where a seismic gap is evident careful and precise research should be carried out.

\subsection{Statistical Expectancy:}

Another useful measure to be employed for deriving the basic earthquake is to use statistical methods. In Japan we 
have several maps showing the statistical expectancy of events related to the maximum earthquake force. For example, the Kawasumi map 4 gives the expected maximum acceleration of earthquakes within 75, 100 and 200 years and the Kanai map gives the expected maximum velocity that will take place at the surface of base stratum by earthquakes within 75, 100, and 200 years. Utilising these statistical studies, we can estimate the seismic intensity, maximum acceleration or maximum velocity which may occur in the base stratum surface of the proposed site.

The values which are obtained from statistical studies may be altered by

(1) the shifting of the location of the epicenter of a large earthquake or modification of magnitude of that earthquake which would be derived from the re-examination of the earthquake data,

(2) the change in the extent of the boundary of the distributed epicenters with which seismic statistics were carried out, and

(3) the change in the chronological period of the earthquake catalogue employed for statistic calculation.

Therefore, if it is required to have the correct statistical expectancy for the maximum acceleration, velocity, etc. at the site, an extremely careful re-examination of the earthquake catalogue as well as the period used in the statistical calculation is needed so that the calculation is based on well-examined complete data.

\subsection{Distant and Near-by Earthquakes}

In deriving the basic design earthquake, both distant and near-by earthquakes should be prudently considered. Especially, in the case of the $S$, basic design earthquake ground motions, the earthquake that may take place almost directly beneath the site area should be taken into consideration.

4. PRACTICAL METHOD FOR THE DERIVATION OF THE MAGNITUDE OF THE BASIC DESIGN EARTHQUAKE

4.1 Derivation of the magnitude of the Strongest Design Eiarthquake, $\mathrm{S}_{1}$ Earthquake

i) Investigation on the historical earthquake

It is now an agreed idea among seismologists that a large earthquake takes place repeatedly at the same site, so basically, the magnitude of the $S$ earthquake can be derived from some historical large earthquakes that has taken place in the vicinity of the site in the past years giving a larger effect to the site than any other earthquake. ii) Investigation on the active fault

The earthquake catalogue may have some missing entry on some important earthquakes, and the possibility should not be overlooked of an important earthquake having such a long recurrence period that in the period covered by the earthquake catalogue the occurrence of that earthquake had not taken place at the specific location. An earthquake originating from an active fault which existed accidentally close to the site area should be taken into consideration when the activity of that active fault is considered very high and is expected to give effect to the site in the near future, in view of the geological evidence and/or engineering judgement. The method with which we evaluate the earthquake from such an active fault is described in Section 5 .

4.2 Derivation of the Magnitude of the $\frac{\text { Extreme Design Earthquake, } \mathrm{S}_{2}}{\text { Earthquake }}$

i) Investigation on the Historical earthquake and on the seismotectonic structures

The magnitude of the $S_{2}$ earthquake can be derived from investigation on the historical earthquake and on the seismotectonic structures which are considered to be specific for each respective region. Considering from the view point of the seismotectonic structure of Japan and from the existing data on the seismic epicenter distribution for the past large earthquakes in Japan. it will be justified to conclude that with respect to each zone in Japan there is an upper boundary for the maximum magnitude of the possible earthquake to be expected to take place in the respective district. In Figure 1 the upper boundary of the

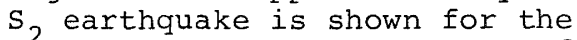
respective zones. Because of the difficulty of fixing the boundary of the seismotectonic structure of Japan, in some areas, it is seen that the lines of distinction of the zones for the different magnitudes of $S_{2}$ earthquakes do not show a closed curve. In the future it is hoped that together with the progress of research in the field of seismotectonics in Japan, some complete map showing the maximum magnitudes for $\mathrm{s}_{2}$ earthquake will come out.

It must be noted that, though the value of maximum magnitude for $S$ earthquakes in each zone is given, it should not lead to 


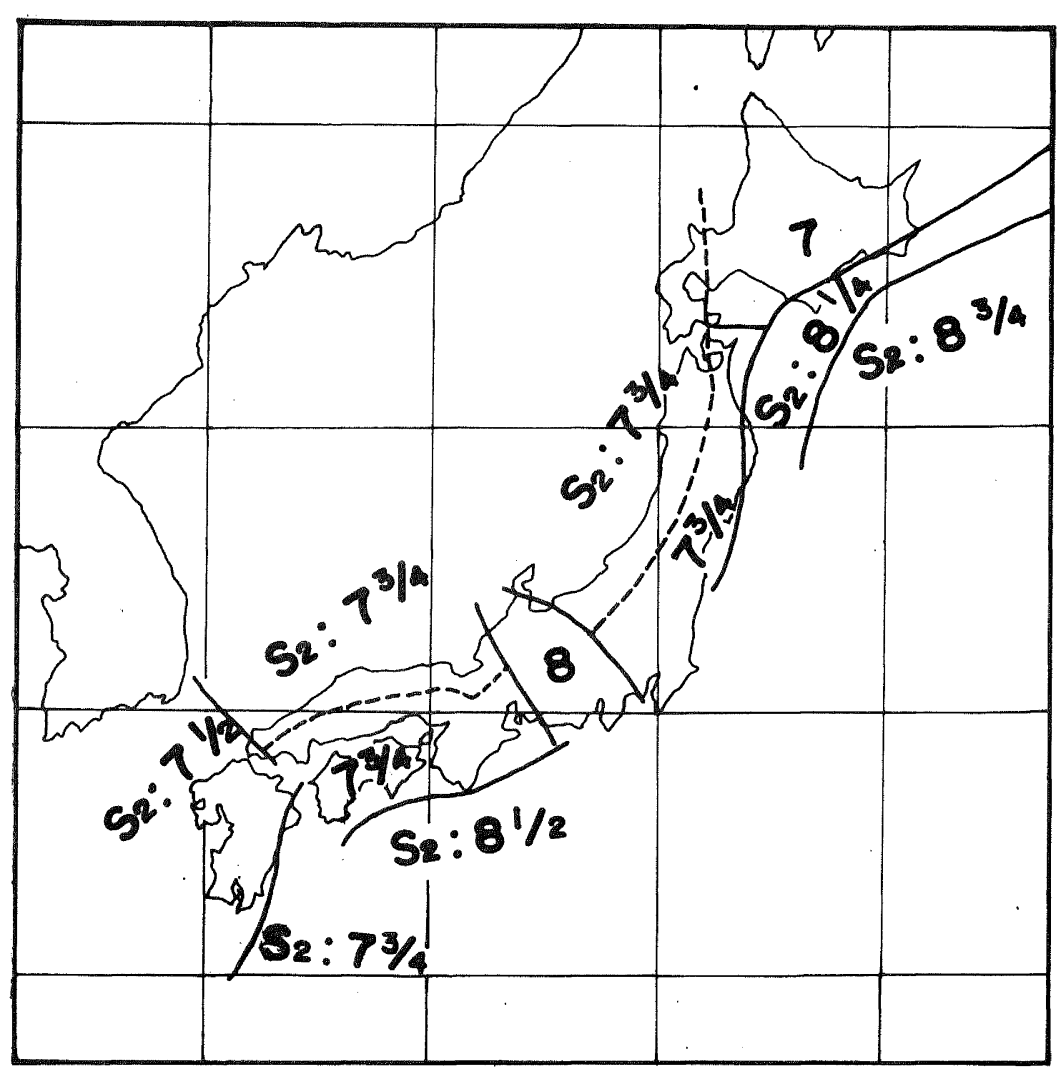

Fig. 1 Upper boundary of the S2 earthquake magnitude is shown for each zone.

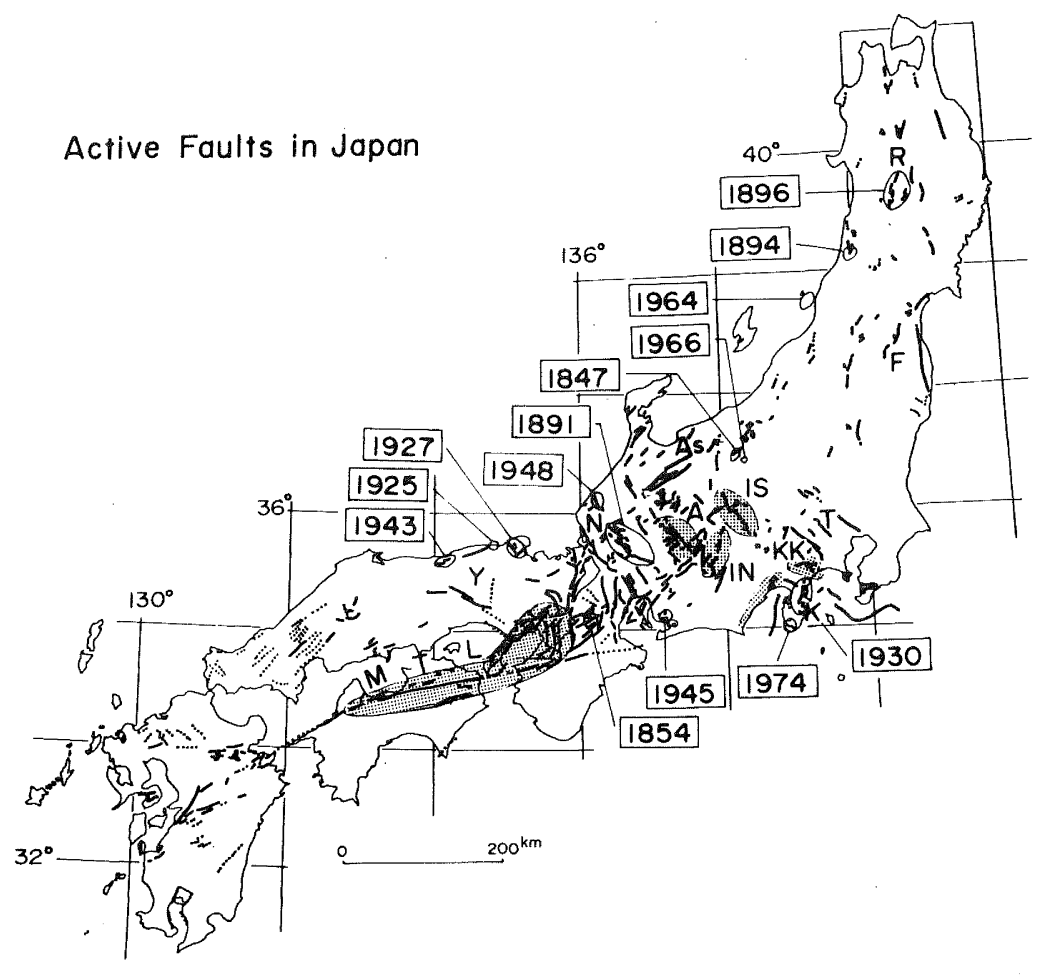

Fig. 2 Distribution of active faults in Japan ( Tter Matsuda ${ }^{7}$ et al). Numbers indicate ages of historic inland earthquakes accompanying surface faulting Stippled fault systems, A, IN, IS, KK and MTL are "precaution faults", which have an elapse ration $E \quad 0.5$. 
the conclusion that, everywhere in each zone the maximum $S_{2}$ earthquake having the largest magnitude designated in each zone can take place. On the occasion when it comes necessary to estimate the $S_{\text {S }}$ earthquake at the specific site, it is greatly important to take into consideration any active fault or faults that exist near the site. The magnitude of an earthquake generated from the specific active fault, and the capacity of that active fault for generating earthquakes in a limited period make up the characteristic nature of that specific active fault. There is a great difference in these characteristics for different active faults. As is well known, some of the active faults have very low probability for generating a future earthquake. Viewing from the engineering standpoint, it is inadequate to take as the $S_{2}$ earthquake of a specific site, an earthquake which might be expected to be generated from an active fault that is considered to have a very, very low probability, only for the reason that an active fault existing near the site has the possibility for generating a very large earthquake.

Therefore, in the case when we are deriving $S$, earthquake from the active faults existing near the site, careful considerations should be paid to the frequent capability of generating large earthquakes from that active fault. Practical ways for taking into consideration the capability of these active faults for generating large earthquakes will be discussed in the next section.

ii) Lower limit of the $\mathrm{S}_{2}$ earthquake

It is well agreed upon in Japan that taking a wide viewpoint, the land of Japan is in one seismotectonic structure. It should be considered that the earthquake of which magnitude is equal to or smaller than 6.5 could take place at ány place in the Japanese islands. Therefore, even in the case when there is no evidence for the existence of an active earthquake fault in the area near the site, and no historical earthquake is located near the site, with respect to any site, an earthquake of magnitude up to 6.5 should be expected to take place at a location very near the site. The minimum level of $\mathrm{S}_{2}$ extreme earthquake for any sitê stands for the earthquake of magnitude
6.5 which may be expected to take place even right underneath of the site.

\section{EVALUATION OF ACTIVE FAULT ${ }^{6}$}

\subsection{Definition}

The term active fault here used is almost in the same meaning as Quaternary faults, which have evidence for displacement during Quaternary time, namely within the last 1.8 million years, and thus they are capable of causing earthquakes in the future.

Judgement as to whether it is an active fault or not will be made through the investigations based upon the topographical and/or geological survey by means of field survey and aerial photographic studies. In recent years along with the progress in the earthquake prediction research programme in Japan, many detailed data have been obtained from the Quaternary faults by using aerial photographs and radiocarbon dating.

\subsection{Active faults in Japan}

In Figure 2 the distribution of the on land active faults in Japan illustrates. As will be seen in Figure 2, several provinces are recognized. Northeastern Honshu is a province of reverse faults, where no major strike-slip faults are present. Central Honshu, including the Chubu and Kinki districts, is characterized by a great number of active faults including both strike-slip and reverse faults. sity of fault population and degree of fault activity in this part of Japan are the highest of all the provinces. In western Japan, the longest and probably the most active strike-slip fault, the Median Tectonic Lone, extends for about $800 \mathrm{~km}$ from central Japan to Kyushu. Except for this, active faults inland in western Japan are few in number and low in activity, particularly so in the outer zone of southwest Japan on the south of the Median Tectonic Line. A transverse volcanic belt in middle Kyushu is an exceptional area characterized by development of normal faults.

There is a general rule in Japan that a majority of thrust faults trend approximately north-south, and the strike-slip faults of left-lateral sense trend northwestsoutheast and those of right-lateral sense trend northeast-southwest. This regularity indicates a maximum compressive crustal stress axis lying in an approximate eastwest direction over the Japanese islands.

Active faults in Japan are generally short in length and distributed rather sparsely or independently. Even when they form a fault system, its dimension is small and less than $100 \mathrm{~km}$ in total length, with an exception of the Median Tectonic Line. The Nobi fault system, for example, which caused the largest historic inland earthquake of 1891, and is called the Nobi earthquake of $M=8$, is only about $80 \mathrm{~km}$ in total length and a few kilometers in 
total displacement. The largest known separation of the basement rocks along active strike-slip faults in Japan is $12 \mathrm{~km}$ along the Itoigawa-Shizuoka Tectonic Line.

In Table 1 major earthquake that accompanied large earthquake faults in Japan are reproduced. The relation between the magnitude and the fault length are shown in Figure 3 . With respect to these earthquake faults, observed in the past earthquakes, the magnitude $M$ is related to the fault length $L$ of the active fault that took place in the generation of that earthquake by the following equation:

$$
\log L=0.6 M_{i}-2.9
$$

\subsection{Classification of Active Faults Based on a Long-term Slip Rate}

Degree of fault activity is reasonably expressed by a long-term average slip rate in the recent geologic past. The average slip rate (S) is obtained from amounts of offset $\left(D_{t}\right)$ of Quaternary geologic or topographic references divided by their age ( $T$ years), that is,

$$
S=D_{t} / T
$$

For example, Figure 4 shows the relation between amounts of offset of dated geologic references and their ages along the central segment (middle and eastern Shikoku) of the Median Tectonic Line. The slip rate of the Miedian Tectonic Line is between 5 and $10 \mathrm{~mm}$ per year during the past about $5 \times 10^{4}$ years. This rate of slip is the highese value so far known inland in Japan, although this is about a half of that of the San Andreas fault in the USA.

Class A faults denote those having an order of one millimeter per year in average slip rate during late Quaternary. Class A faults are known mostly from strike-slip faults in central Japan. Most of reverse faults developed in northern Honshu belong to class B faults having an order of $0.1 \mathrm{~mm}$ per year in slip rate.

Class A and class B faults have usually distinct topographic expressions, so that they are easily detectable means of aerial photographs. Class C faults are less distinctive and are often overlooked or difficult to distinguish from lineaments other than those of tectonic origin.

Class AA faults, having larger than $10 \mathrm{~mm}$ per year in slip rate, are not known yet on land in Japan, but a megathrust (the Nankai thrust) along a converging plate boundary off southwest Japan has been inferred to have an average slip rate of this class.

Although no quantitative data are available for many faults, it seems correct to say that most faults mapped in Figure 1 are of either class A or B. Active faults of class $C$ are considered to be mostly excluded in the map, unless they are long enough to be detectable and mappable.

\subsection{Recurrence time. of Historic Earthquakes in Japan}

Geologically-known displacement along a fault can be assumed in Japan to be an accumulation of intermi-tent sudden slips associated with earthquakes, because fault creep has not been observed along any active faults in Japan except for fault slippage immediately after great earthquakes. Thus, recurrence time of earthquakes from a given segment of fault is obtained from an equation,

$$
R=D / S
$$

where: $\quad R=$ recurrence time, $D=$ displacement accompanying an earthquake, $\mathrm{S}=$ longterm slip rate. shown in Figure 5.

Value $D$ is related to earthquake magnitude $M$. The relation between $D$ and $M$ for historic major earthquakes on land in Japan is shown in an equation,

$$
\log \mathrm{D} \text { (meter) }=0.6 \mathrm{M}-4.0
$$

T'hus, from Eqs. (3') and (4), with $S$ in meter/year,

$$
\log R=0.6 M-(\log S+4.0)
$$

A diagram of Figure 6 is drawn from Eqs. (3) and (4), in which a relation between $R$ and $D$ or $M$ is shown for various values of $S$. As seen in the diagram, recurrence time of earthquakes of magnitude 8 from class A faults ranges 0.6 - $6 \times 10^{3}$ years. From faults of lower classes, recurrence time becomes one order longer successively, namely $0.6-6 \times 10^{4}$ years for class B faults and $0.6-6 \times 10^{5}$ years for class $C$ faults. In case of magnitude 7 , the recurrence time of earthquakes becomes one fourth of those for magnitude 8 , respectively.

Using a value $D$ or $M$ of historic earthquake from active faults, we can obtain a recurrence time of earthquakes from the respective fault. The Kita-Izu fault system, for example, which caused the Kita-Izu earthquake of 1930, has about $1,000 \mathrm{~m}$ in displacement during the past $0.5 \mathrm{~m} \cdot \mathrm{y} .\left(\mathrm{S}=2 \mathrm{~m} / 10^{3}\right.$ year $)$ and moved about $2-3 \mathrm{~m}$ during the 1930 earthquake in the same sense (left-lateral) as that of an accumulated displacement during late Quaternary. Thus, the recurrence interval of such events as the 1930 earthquake has been estimated at about 1,000 years.

Recurrence times for major historic earthquakes accompanying surface faulting in Japan are calculated and shown in Table 1. It can be said roughly that 

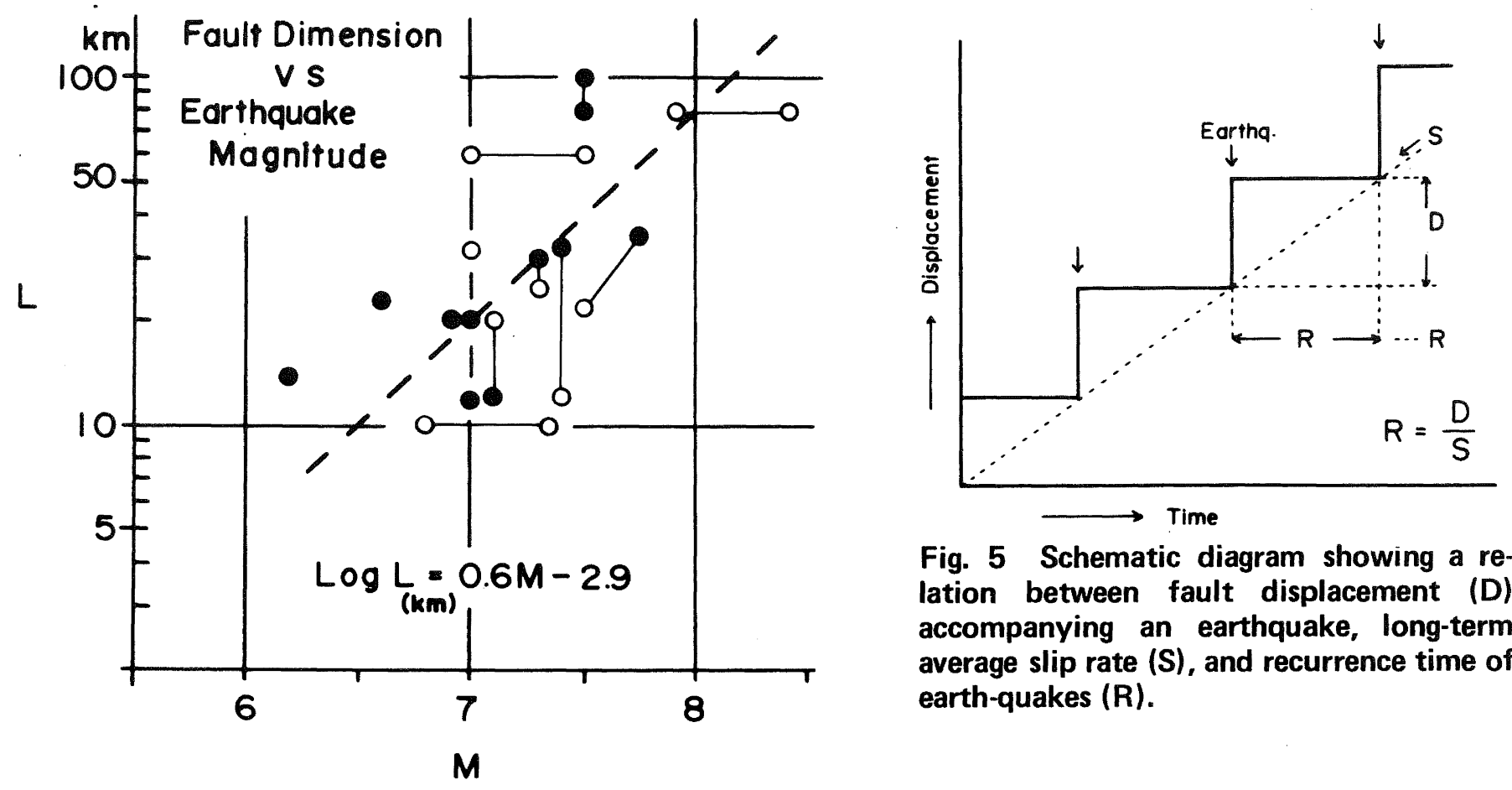

Fig. 5 Schematic diagram showing a relation between fault displacement (D) accompanying an earthquake, long-term average slip rate $(S)$, and recurrence time of earth-quakes $(R)$.

Fig. 3 Fault dimension and earthquake mangitude.
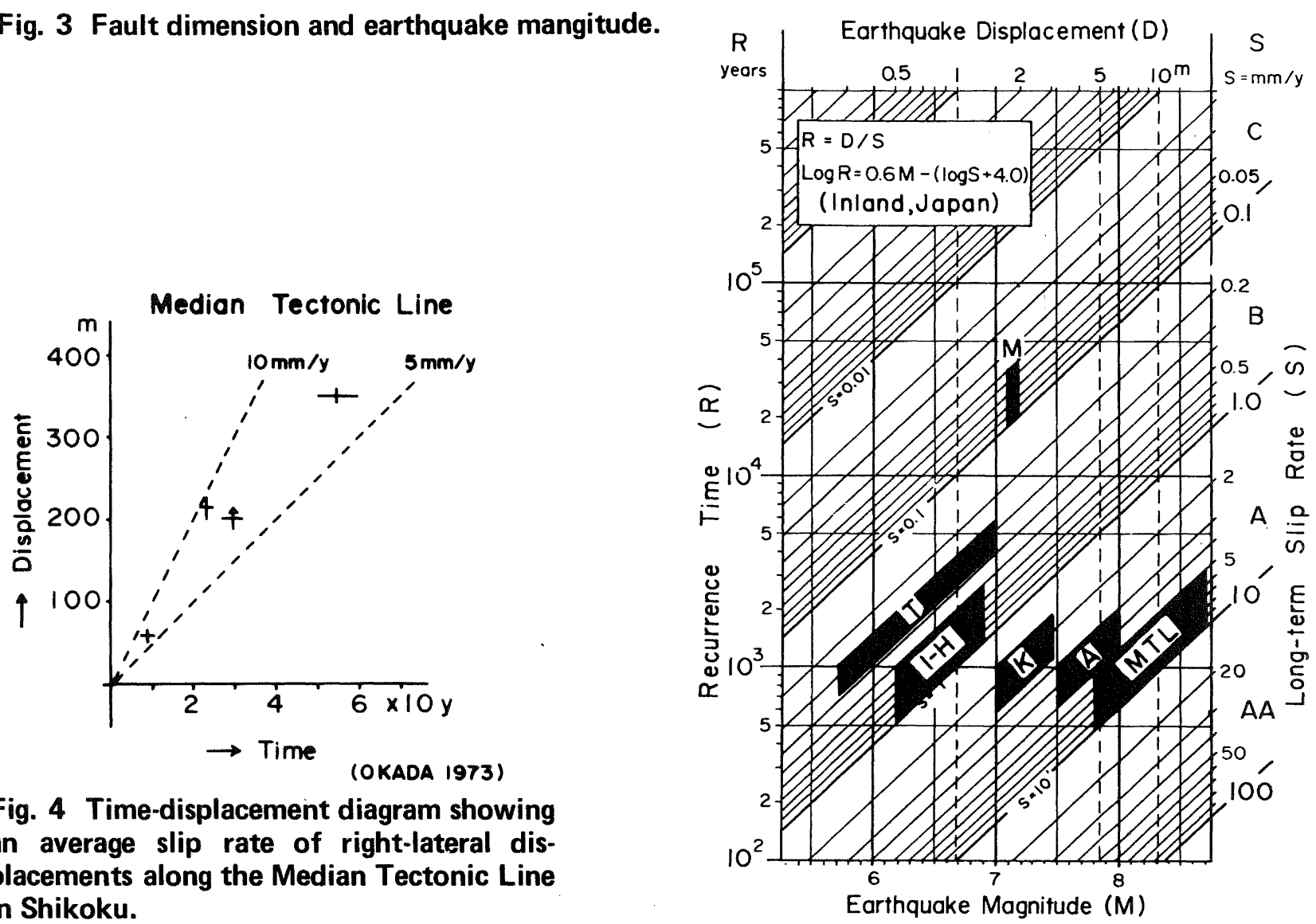

Fig. 4 Time-displacement diagram showing an average slip rate of right-lateral displacements along the Median Tectonic Line in Shikoku.

Fig. 6 Diagram showing recurrence times in relation to earthquake magnitude or earthquake displacement for fault with various values of a long-term slip rate. Examples are shown for some active faults with historic earthquake (I-H, $\mathrm{K}$ and $\mathrm{M})$ and without historic earthquakes (A, MTL and T). For data of each fault, see Tables 1 and 2. A. Atera fault; I-H, Irozaki fault (Izu-Hanto-oki earthquake, 1974); K, Kita-Izu fault system (Kita-Izu earthquake, 1930); M, Fukozu fault (Mikawa earthquake, 1945); MTL, central segment of Median Tectonic Lines; T, Tachikawa fault. 
recurrence time of the historic destructive earthquakes large enough to be associated with surface break is of order of thousands of years if the casual ective faults of class A or class B, and of order of tens of thousands of years if it is of class C.

\subsection{Estimation of earthquake magnitude from a fault}

When an active fault has no record of historic faulting, either probable earthquake magnitude or a probable fault displacement accompanying an earthquake must be estimated in order to get the recurrence time of earthquakes from the fault. A displacement in a single episode of faulting for a given faultsegment ( $D$ in Eq. (3)) may be obtained from an offset or a set of offsets of geologic references. Earthquake magnitude $M_{D}$ corresponding to $D$ (meter) is, from Eq. (4),

$$
M_{D}=(\log D+4.0) / 0.6
$$

$M_{D}$ gives an upper limit of possible magnitude if the $D$ was taken from the main part of the fault segment, because $D$ may involve more than one event of faulting. For example, the Tachikawa fault, about $20 \mathrm{~km}$ long, in the western suburb of Tokyo, offsets three different alluvial terraces about $1.4,3.6-3.8$ and $5.2 \mathrm{~m}$ respectively, in an older order of age of the terraces. In this case, $1.3-1.4 \mathrm{~m}$ seems adequate as value of $D$ at the locality. which gives $\mathrm{M}_{\mathrm{D}}$ about 7 in Eq. (6).

More common is a case in which we have no good data to restrict value $D$. In those cases, the earthquake magnitude from an active fault can be estimated from combining the following two ways: one is an estimate of magnitude $M$ from length of the fault $\left(L_{t}\right)$ using Eq. (2),

$$
M_{L}=\left(\log L_{t}+2.9\right) / 0.6
$$

Lt in Eo. (7) may include two or more segments, from which smaller earthquakes occur. Thus, M gives a value of the upper limit for $L$ probable magnitude expectable from a $L_{t} \mathrm{~km}$-long fault.

The second way to estimate is from length of time $(t)$ elapsed without earthquakes from the fault up to the present. Value $t$ is obtained in most cases from historic documents, and possibly from age of unfaulted oldest sediments overlying the fault. Assuming that the earthquake energy has linearly increased with the lapse of time, earthquake magnitude $M_{t}$ corresponding to the earthquake during $t$ years is calculated from Eq.

(5), substituting $R$ with $t$,

$$
M_{t}=(\log t+\log s+4.0) / 0.6
$$

Magnitude $M_{t}$ represents the lower limit of probable magnitude of a future earthquake, because $t$ is smaller than the interval between the previous and next earthquake. Then,

$$
M_{t}<M_{\text {prob }} \leq M_{L^{\prime}}{ }^{M_{D}}
$$

For example, the central segment of the Median Tectonic Line, which is 5-10 mm/year in S (Fig. 3), has had no great earthquakes during the past at least 1.000 years. Earthquake energy stored during this non-earthquake period $t$ corresponds to magnitude 7.8 to 8.3 from Eq. (8). The length of the segment is about $200 \mathrm{~km}$, which corresponds, from Eq. (7), to magnitude $M_{L}=8.7$. Thus, probable magnitude $M_{\text {prob }}$ for the segment is inferred from Eq. (9) to be 7.8 $<M_{\text {prob }} \leq 8.7$. Thus, we can expect great earthquakes of as large as magnitude 8 from the segment. Then, calculated recurrence time of such great earthquakes is 600-1,300 years from Eq. (5).

As is shown above, it is possible to estimate probable magnitude and recurrence time of earthquakes from a given segment of fault system, if we have values of $S, I, D$, and/or $t$ for a given fault. Estimated magnitude and recurrence time for some of major active faults in Japan are shown in Table 2 .

\subsection{Active fault related to $S_{1}$ earthquake}

Basing upon these discussions given in previous sections, in the case when it is considered that an active fault exists near the site, the potential capability of this active fault for generating $S_{\text {, }}$ earthquake can be judged in the light of the following criteria (i), (ii) and (iii).

(i) All the active faults that we can identify as having generated earthquakes in the historical age in Japan.

(ii) Among the class A active faults, those which are considered to shown clear evidence that they have moved in the period less than 10,000 years, or those of which recurrence years are shorter than 10,000 years.

(iii) Active faults of which seismic activity along the fault surface can be clearly detected by means of the micro-earthquake observations.

\subsection{Active Fault related to $\mathrm{S}_{2}$ Earthquake}

Active faults that satisfy the following criteria (i) and (ii) are considered to have the potential capability for generating $\mathrm{S}_{2}$ earthquake.

(i) All active faults except those that fall in the categories shown in (i) and (ii) in the section $5-6$.

(ii) Among the active faults that belong to class $B$ and class $C$ active faults, those of which activity can be clearly verified within the period of 50,000 years 
TABLE 1 RECURRENCE TIME OF SOME HISTORIC EARTHQUAKES INLAND IN JAPAN

\begin{tabular}{|c|c|c|c|c|c|c|c|c|c|}
\hline \multicolumn{4}{|c|}{ Earthquake } & \multicolumn{3}{|c|}{ Quaternary fault } & \multicolumn{2}{|c|}{$\begin{array}{l}\text { Recurrence time } \\
R \text { (year) from }\end{array}$} & \multirow{2}{*}{$\begin{array}{l}\text { Previous } \\
\text { earthquake } \\
\text { recorded in } \\
\text { history }\end{array}$} \\
\hline Data & Name & $M$ & $D(\mathrm{~m})$ & $S(\mathrm{~m} /$ year $)$ & $L_{t}(\mathrm{~km})$ & $L / L_{t}^{*}$ & Eq. (2) & Eq. (4) & \\
\hline 1891 & Nobi & 7.9 & 8 & $1-5 \times 10^{-3}$ & 80 & $\approx 1$ & $1-5 \times 10^{3}$ & $1-8 \times 10^{3}$ & A.D. $745(M=7.9)$ \\
\hline 1896 & Riku-U & 7.0 & 3 & $0.5-1 \times 10^{-3}$ & 60 & $\approx 1$ & $2-3 \times 10^{3}$ & $3-6 \times 10^{3}$ & - \\
\hline 1927 & Tango & 7.5 & 3 & $0.5-1 \times 10^{-4}$ & 18 & $\approx 1$ & $3-6 \times 10^{4}$ & $3-6 \times 10^{4}$ & - \\
\hline 1930 & Kita-Izu & 7.0 & 3 & $1.5-2.5 \times 10^{-3}$ & 30 & $\approx 1$ & $1-2 \times 10^{3}$ & $0.6-1 \times 10^{3}$ & A.D. $841(M=7.0)$ \\
\hline 1943 & Tottori & 7.4 & 1.5 & $0.5-1 \times 10^{-4}$ & 8 & $\approx 1$ & $3-6 \times 10^{4}$ & $2-3 \times 10^{4}$ & - \\
\hline 1945 & Mikawa & 7.1 & 2 & $0.5-1 \times 10^{-4}$ & 20 & $\approx 1$ & $2-4 \times 10^{4}$ & $2-4 \times 10^{4}$ & - \\
\hline 1974 & Izu-Hanto-oki & 6.9 & 0.5 & $0.5-1 \times 10^{-3}$ & 5.5 & $\approx 1$ & $1-3 \times 10^{3}$ & $0.5-1 \times 10^{3}$ & - \\
\hline
\end{tabular}

* Ratio of length $(L)$ of historic surface break to total length $\left(L_{t}\right)$ of the fault system.

TABLE 2 CALCULATED PROBABLE MAGNITUDE ( $\mathbf{M}_{\text {prob) }}$ AND RECURRENCE TIME (R) OF EARTHQUAKES FROM SOME ACTIVE FAULTS IN JAPAN

\begin{tabular}{|c|c|c|c|c|c|c|c|c|}
\hline & $\begin{array}{c}S \\
(\mathrm{~mm} / \text { year })\end{array}$ & $\begin{array}{c}\left.t^{I}\right) \\
\text { (years) }\end{array}$ & $\begin{array}{c}L_{t} \\
(\mathbf{k m})\end{array}$ & $M_{t}$ & $\underset{\text { hagni }}{M_{L}}$ & $\begin{array}{l}M_{\text {prob }} \text { I) } \\
\text { ude) }\end{array}$ & $\underset{\text { (years) }}{R}$ & $t / R$ \\
\hline $\begin{array}{l}\text { Median Tectonic Line, } \\
\text { central segment }\end{array}$ & $5-10$ & 1,000 & 200 & $7.8-8.3$ & 8.7 & 8 & $1,262-631$ & $0.8-1.6$ \\
\hline Atera fault $\pi$ ) & $3-5$ & 1,000 & 60 & $7.5-7.9$ & 7.8 & 8 & $2,103-1,262$ & $0.5-0.8$ \\
\hline Tachikawa fault $\left.^{\nabla}\right)$ & $0.25-0.35$ & 1,000 & 20 & $5.7-5.9$ & 7.0 & 7 & $6,340-4,528$ & $0.16-0.22$ \\
\hline $\begin{array}{l}\left.\text { Fukushima fault, }{ }^{\pi}\right) \\
\text { southern segment }\end{array}$ & $0.4-0.8$ & 1,000 & 25 & $6.0-6.5$ & 7.2 & 7 & $3,963-1,981$ & $0.25-0.50$ \\
\hline $\begin{array}{l}\text { Kozu-Matsuda- } \\
\text { Kannawa fault system }\end{array}$ & II) $1-2$ & 1,000 & 20 & $6.7-7.2$ & 7.0 & 7 & $1,585-792$ & $0.6-1.26$ \\
\hline
\end{tabular}

I) $t$ is assumed 1,000 years for faults with no recorded earthquake in history of Japan.

II) $\mathrm{M}_{\text {prob }}$ is given in a probable round number from $\mathrm{M}_{t}$ and $\mathrm{M}_{L}$, which are used for calculation of $\mathrm{R}$

III) Okada9)

IV) Sugimura and Matsuda ${ }^{10}$

V) Yamazakill)

VI) Otsuki et al? 2)

VII) Machida and Moriyama, ${ }^{13}$ Machida et al ${ }^{14}$ ) 
or of which recurrence years are shorter than 50,000 years.

\section{EVALUATION OF BASIC DESIGN EARTHQUAKE} GROUND MOTIONS:

\subsection{Earthquake Ovservation in the Site Area}

For the purpose of evaluating the earthquake force that effects the site, the most pertinent expression on the earthquake force can be obtained by designating three parameters in the ground vibration at the site due to the earthquake. These three parameters are: Maximum amplitude, frequency characteristics and the time-dependent variation of the amplitude envelope curve.

These three parameters that stand for the most effective and definite expression for the earthquake force are deeply related to the magnitude of the earthquake, the distance between the site and source, and geological or geomechanical property of the base stratum. Appropriate knowledge of these three parameters can be provided from the earthquake records observed at the site area.

For this purpose nowadays earthquake observations are being carried out at many nuclear power plant sites. Unfortunately however, the seismic records obtained in this way at these sites are usually the records of very small earthquakes. On the occasion when it is intended to utilize these data obtained at the site for determining the three parameters mentioned above, careful considerations should be called upon for notifying the differences involved in the vibration characteristics between these small amplitude earthquake motions and real large earthquake motions.

\subsection{Distance Between the Site and the Energy centre of an Earthquake}

The distances between the centers of energy release of the maximum or extreme design earthquakes and the site are determined by considering the centers of energy release in past earthquakes, the locations of nearby active faults, and the seismo-tectonic structures. The relationship between the site and various earthquakes are to be expressed in terms of the distance between the centers of energy release and the site.

However, in order to give a quantitative expression for the attenuation of earthquake energy with distance from the earthquake origin, several mathematical formulae have been proposed by many authors. In the course of the calculation for the earthquake effect at the site, utilising these formulae, the first problem we must encounter is to determine the point from which we assume the earthquake energy has been sent out. If the distance between the site and source is fairly distant, then the center of the earthquake energy release can be replaced by the hypocenter which is determined from the instrumental seismology, giving almost no trouble. But in the case when the distance between the site and earthquake source is very short, which is the case we must deal with usually, there comes out quite a large difference on the earthquake effect given to the site, in accordance with the difference in the assumption on from which part of the large fault surface the earthquake energy has been sent out.

In the future it can be expected that a much more reasonable way of calculation will be developed so that the earthquake effect at the site can be evaluated as an integrated effect of the acceleration or velocity amplitudes of the ground motion which were generated at the earthquake source as an event of the fault rupture in the form of a sunning source. Presently, however, such a way of calculation is still under way of exploitation, so practically it is assumed that the geometrical center of the fault surface is taken as the center of the earthquake energy release.

\subsection{Three Parameters}

(i) Maximum amplitude of the earthquake ground motions

We are proposing that the best way of expressing the maximum amplitude of the earthquake ground motions is the velocity amplitude. In general, however, in the period range of very high frequency, the acceleration amplitudes become enormously large giving significant effect to the building structures and to the equipment and pipings, so careful and specific attention should be paid in the designing for such cases.

The maximum horizontal velocity amplitude at the free field of the base stratum surface at the site due to the earthquake of known magnitude and distance can be calculated from the empirical formulae worked out from the actual observations of earthquake amplitude or from the theoretical analysis carried out for the near field fault model solutions. As the empirical formulae based upon the actual seismic observations, Kanai's equations 15 are widely employed in Japan.

$$
\begin{aligned}
V_{\max }= & 100.61 \mathrm{M}-\left(1.66+\frac{3.6}{\mathrm{x}}\right) \log \mathrm{x}- \\
& \left(0.631+\frac{1.83}{\mathrm{x}}\right)
\end{aligned}
$$

where $V_{\max }$ represents the maximum velocity on the surface of the base stratums (kine) $\mathrm{M}$ the magnitude and $\mathrm{x}$ the hypocentral distance.

Kanai's equations are established in their validity for the sites outside of the epicentral region for the earthquakes of any magnitude. Inside the epicentral region, however, it is known that, in general, they give a value too large. For this reason, in the case when it is required to evaluate the earthquake force at the location very 
close to the earthquake source, it may be advisable to give some correction to the value obtained from the mathematical calculation by means of Kanai's equation, in consultation with the characteristic natures of the ground vibrations known at the epicentral region, or to make direct evaluation of the earthquake force at the location near the earthquake source referring to the actual earthquake damage observed in the epicentral area for the past earthquakes.

(ii) Frequency characteristics of the earthquake ground motion

The frequency characteristics of the earthquake motion at a site depend upon the magnitude of the earthquake, distance between the site and the center of energy release and the vibrational characteristics of the base stratum. Therefore, for the purpose of obtaining the frequency characteristics at the site area due to an expected earthquake, the three elements mentioned in the above paragraph provide leading materials, but at the same time the earthquake records observed at the base stratum of the site, time histories of the microtremor records at the site, and other seismographic observation records at the locations having the like base stratum structures - all these materials will provide greatly important and available data for evaluating the frequency characteristics to be expected at the site area.

(iii) Duration and time-dependent variation of amplitude envelope curves

As to the duration time of the earthquake ground motions, the total time from the onset of the earthquake energy input to the end of the vibrational waves on the seismograms should be measured. It is already established that there is a close relation between the magnitude of an earthquake and the duration time of the earthquake ground vibration at the site of definite distance or the envelope curve of the vibration amplitude at that site. Therefore, in evaluating the duration time or shape of the envelope curve of the ground vibration amplitude at a site, these should be evaluated in accordance with the magnitudes of the maximum strong design earthquake or the extreme design earthquake, respectively.

\section{REFERENCES:}

1. Usami, T., Summary of the Damaging Earthquakes of Japan (in Japanese) Tokyo University Press, 1975.

2. The Central Meteorological Observatory, The Catalogue of Major Earthquakes which occurred in Japan (1885-1950). The Seis. Bull. Central Meteor. Obs. Japan 1952, pp 99-184.

3. Japan Meteorological Agency, Catalogue of Major Earthquakes which occurred in and near Japan
(1926-1956): Seis. Bull. JMA supp., Vol. No. 1 (1958), pp. $1-91$.

4. Kawasumi, H., Measures of Earthquake Danger and Expectancy of Maximum Intensity Throughout Japan as Inferred from the Seismic Activity in Historical Time. Bull. Earthq. Res. Inst., Vol. 29 (1951), pp. 469-482.

5. Kanai, K. et al, Expectancy of the Maximum Velocity Amplitude of Earthquake Motions at Bed Rock. Bull. Earthq. Res. Inst., Vol. 46 (1968), pp. 663-666.

6. Matsuda, T.. Estimation of Future Destructive Earthquakes from Active Faults on Land in Japan. Journal Phys. Earth., Vol. 25 Supplement 1977, pp. 251-260.

7. Matsuda, T., A. Okada, and K. Huzita, Distribution map and catalogue of active faults in Japan, Mem. Geol. Sec. Japan. 12, 1976. pp.185-198.

8. Matsuda, T., Magnitude and Recurrence Interval of Earthquakes from a Fault (in Japanese). Zisin, Journal Seism. Soc. Japan Vol. 28 No. 3 (1975), pp. 269-283.

9. Okada, A., On the Quaternary faulting along the Median Tectonic Line, in Median Tectonic Line, pp. 49-86. Tokai Univ. Press, Tokyo, 1973.

10. Sugimura, A. and T. Matsuda, Atera fault and its displacement vectors, Geol. Sec. Am. Bull., 76, 1965 pp. 509-522.

11. Yamazaki, H., Taxhikawa fault on the Musashino Upland and its late Quaternary movement, Quaternary Res. (Daiyonki-Kenkyu), 1977 (in press).

12. Otsuki, K., T. Nakata, and T. Imaizumi, Quaternary crustal movements and block model in the southern region of the northeast Japan, Earth Sci. (Chikyu Kagaku), 31, 1977 pp.1-14.

13. Machida, H. and A. Moriyama, The Development of Mt Fuji and Mt Hakone volcanoes analysed from the Tephrochronological study in the Ooiso Hills, Geogr. Tev. Japan, 41, 1968 pp. 241-257.

14. Machida, H., Y. Matsushima, and I. Imanaga, Tephrochronological Study on eastern foot of Mt Fuji Volcano - with special reference to geomorphological development accompanied with growth of Mt Fuji and displacement of the Kannawa fault, Quaternary Res. (Daiyonki-Kenkyu), 14, 1975 pp. 77-89.

15. Kanai, K., Observation of Strong Earthquake Motions in Matsushiro Area. Part 1 (Empirical Formulae of Strong Earthquake Motions). Bull. 
Earthq. Res. Inst., Vol. 44

(1966), pp. 1269-1296.

16. Hisaka, T., Y. Ohsaki, M. Watabe and $T$. Ohta, Design Spectra for Stiff Structures on Rock. Proc.

2nd Intern. Conf. Microzonation,

1978, San Francisco, Calf. USA.

This paper is a slightly modified version of the paper titled "A New Proposal

for Estimating the Expected Maximum

Earthquake Force at a Nuclear Power

Plant Site" presented at the South Pacific

Regional Conference on Earthquake

Engineering, Wellington May 1979. 